\title{
Особенности течения травматической болезни при огнестрельных и колото-резаных ранениях живота
}

\author{
С.Е. Урядов, В.Р. Горбелик, Т.Ч. Аллахяров, М.А. Шихмагомедов, \\ С.А. Куликов, А.В. Куликов \\ Филиал частного учреждения образовательной организации высшего образования \\ «Медицинский университет «Реавиз» в городе Саратов, \\ Россия, 410012, г. Саратов, ул. Верхний Рынок, 10 \\ E-mail:maslyakov@inbox.ru
}

\begin{abstract}
Аннотация. В статье представлены результаты исследований по изучению ближайшего послеоперационного периода 185 раненых, при этом огнестрельные ранения были у 89 (48,1\%), а колото-резаные - у 96 (51,9\%). Проведенные исследования показывают, что травматическая болезнь при различных ранениях живота протекает по-разному и в различных временных рамках. В результате проведенных исследований было установлено, что при колото-резаных ранениях живота травматическая болезнь протекает более легко и быстрее, чем при огнестрельных ранениях живота, это проявляется как клинически, так и лабораторными показателями. При этом, по нашим данным, развитие травматической болезни было зарегистрировано при изолированных повреждениях живота, в случаях оценки состояния тяжести по шкале ВПХ-СП при колоторезаных ранениях в $19 \pm 0,7$ баллов, а при огнестрельных ранениях - в $23 \pm 0,7$ балла, что необходимо учитывать при ведении таких раненых. Всё это требует дальнейшего исследования.
\end{abstract}

Ключевые слова: ранения живота, ближайший послеоперационный период, травматическая болезнь.

Для цитирования: Урядов С.Е., Горбелик В.Р., Аллахяров Т.Ч., Шихмагомедов М.А., Куликов С.А., Куликов А.В. 2020. Особенности течения травматической болезни при огнестрельных и колото-резаных ранениях живота. Актуальные проблемы медицины, 43 (3): 455-464. DOI: 10.18413/2687-0940-2020-43-3-455-464

\section{Peculiarities of traumatic disease course in gunshot and stab-cut abdominal injuries}

\author{
Sergej Ye. Urjadov, Viktor R. Gorbelik, Tengis C. Allahjarov, Murat A. Shihmagomedov, \\ Sergej A. Kulikov, Aleksandr V. Kulikov \\ Branch of private institution of educational organization of higher education \\ «Reaviz Medical University» in the city of Saratov, \\ 10 Upper Market St., Saratov, 410012, Russia \\ E-mail: maslyakov@inbox.ru
}

\begin{abstract}
The article presents the results of research on the nearest postoperative period of 185 wounded, with gunshot wounds in $89(48,1 \%)$ and coloto-cut injuries in $96(51,9 \%)$. Studies have shown that traumatic disease in various abdominal injuries occurs differently and within different time frames. As a result of the studies carried out, it was found that traumatic disease is more easy and faster in coloto-cut abdominal injuries than in gunshot wounds of the abdomen, it is manifested by both clinical and laboratory indicators. At the same time, according to our data, the development of traumatic disease was registered in isolated abdominal injuries, in cases of assessment of the state of severity on the scale of HPV-SP in coloto-cut wounds of $19 \pm 0,7$ points, and in gunshot wounds - of $23 \pm 0,7$ points. All this must be taken into account in the conduct of such wounded and requires further study.
\end{abstract}


Keywords: abdominal injuries, immediate postoperative period, traumatic disease.

For citation: Urjadov S.E., V.R. Gorbelik, Allahjarov T.Ch, Shihmagomedov M.A., Kulikov S.A., Kulikov A.V. 2020. Peculiarities of traumatic disease course in gunshot and stab-cut abdominal injuries. Challenges in Modern Medicine, 43 (3): 455-464 (in Russian). DOI: 10.18413/2687-0940-2020-43-3-455-464

\section{Введение}

В составной части структуры травматических повреждений травмам живота отводится до $10 \%$ от числа всех травм [Масляков и др., 2014]. При этом доказано, что неблагоприятные исходы при таких ранениях обусловлены не столько характером повреждений внутренних органов, сколько наличием или отсутствием сочетанных повреждений и шоком [Эрметов и др., 2017; Стяжкина и др., 2018]. Ранения живота приводят к развитию тяжелой травматической болезни, которая характеризуется большей длительностью, увеличением цифр летальности, обусловленных наиболее частым развитием тяжелого сепсиса [Штейнле, 2010; Самохвалов и др., 2018]. Вместе с тем имеется множество нерешенных вопросов, посвященных проблеме течения травматической болезни при абдоминальных ранениях, одна из которых - особенности течения при различных ранениях в сравнительном аспекте.

Цель исследования - изучение особенностей течения травматической болезни при абдоминальных ранениях в зависимости от характера ранения.

\section{Материалы и методы}

Работа основана на анализе ближайшего послеоперационного периода 185 раненых, которые поступили в экстренном порядке в лечебные учреждения 9-й городской больницы г. Грозного и больницы скорой медицинской помощи г. Энгельса в период с 2003 г. по 2018 г. У данных раненых в момент поступления были диагностированы проникающие ранения живота. Преобладали раненые мужского пола - 151 (81,6 \%), женского пола было всего 34 (18,4\%) человека. При этом огнестрельные ранения были у 89 $(48,1 \%)$, а колото-резаные - у 96 (51,9\%). Преобладали молодые лица, средний возраст которых составил $25 \pm 5$ лет.

В исследования были включены раненые с изолированными, одиночными ранениями в живот, внутрибрюшная кровопотеря не превышала 200-500 мл. Учитывались огнестрельные пулевые ранения, а также одиночные колото-резаные ранения, проникающие в брюшную полость, время доставки которых в лечебную организацию от момента получения ранения не превышало одного часа. Исключались раненые с сочетанными и множественными ранениями, дробовые, осколочные и минно-взрывные ранения, раненые с внутрибрюшным кровотечением, превышающим 500 мл, раненые, доставленные позже 1 часа от момента получения ранения, имеющие признаки разлитого перитонита, находящиеся в агональном состоянии.

Расчеты кровопотери проводили с использованием методики, предложенной Moore [Тимербулатов и др., 2012]. Для определения кровопотери учитывали такие факторы, как цифры артериального давления, пульс, количество суточного диуреза, центральное венозное давление (ЦВД), которое определяли с помощью прямого способа измерения венозного давления по Moritz и Tabora. Проводили подсчет количества эритроцитов в периферической крови и количества гемоглобина.

В момент поступления раненым проводилась первичная хирургическая обработка раны (ПХО) под местной анестезией, при которой устанавливалось наличие проникающего ранения в брюшную полость, что являлось показанием для выполнения лапаротомии под эндотрахеальным наркозом с искусственной вентиляцией легких. Отсутствие повреждения внутренних органов при ревизии брюшной полости было выявлено всего лишь у 
32 (17,3\%) человек от общего количества раненых. При этом наиболее часто - 21 (21,9\% от числа раненых в этой группе). В группе с огнестрельными ранениями отсутствие повреждений внутренних органов выявлено лишь у 11 (12,4 \% от числа пострадавших в этой группе). В остальных 153 (82,7 \%) наблюдениях были отмечены ранения внутренних органов. Ранения полых органов (желудок, тонкая и толстая кишка) были зарегистрированы в 79 (42,7 \%) наблюдениях. Ранения паренхиматозных органов (печень, селезенка) были отмечены в 74 (40\%) случаях.

В работе была использована 3-степенная классификация шока. Тяжесть ранений и кровопотеря закономерно приводили к развитию шока. Так, в состоянии шока различной степени тяжести в медицинскую организацию были доставлены 89 (48,1\%) раненых. Из них в группе с огнестрельными ранениями живота - 54 (29,2 \%) раненых, а в группе с колото-резаными ранениями - 35 (18,9\%) человек. Из общего числа раненых, доставленных в состоянии шока, шок I степени - у 23 (12,4 \%), II степени - у 55 (29,7 \%), III степени был зарегистрирован у $11(5,9 \%)$ раненых.

Восполнение кровопотери и ОЦК осуществлялось с помощью кристаллоидов, полиглюкина. Проведение гемотрансфузии не выполнялось.

Оценка тяжести состояния осуществилась с помощью шкалы ВПХ-СП [Гуманенко и др., 1999].

Определение концентрации С-реактивного белка в сыворотке крови осуществлялось иммунотурбидиметрическим методом. Для исследования эндотоксикоза использовалось изучение показателей перекисного окисления липидов (ПОЛ). Для этого определяли уровень малонового диальдегида, супероксид-дисмутазы эритроцитов, мочевины, креатинина, а также общую антиоксидантную активность. Определение малонового диальдегида осуществляли с помощью теста с добавлением тиобарбитуровой кислоты по методу, предложенному Стальной И.Д и Гаришвили Т.Г. [Стальная, Гаришвили, 1977]. Активность супероксид-дисмутазы эритроцитов выполняли с помощью спектрофотометрического метода, предложенного Н.P. Misra и J. Fridovich (1972) и модифицированного О.Г. Саркисяном (2000). Полученные результаты выражались в условных единицах на 1 г гемоглобина. Уровень мочевины и креатинина в сыворотке крови изучались с использованием прибора фотоэлектроколориметра КФК-3.

Группу сравнения составили 25 относительно здоровых доноров-добровольцев того же возраста и пола.

Согласно требованиям к проведению исследований, предъявляемым Хельсинкской декларацией Всемирной медицинской ассоциации (WMA Declaration of Helsinki - Ethical Principles for Medical Research Involving Human Subjects, 2013), перед началом исследования все пациенты давали письменное согласие для участия в исследовании. Выполнение исследования было согласовано и получило одобрение комиссии, занимающейся вопросами биоэтики.

Полученные данные обрабатывали методом вариационной статистики медикобиологического профиля. Обработка включала расчет медиан и верхних и нижних квадрилей, а также определение достоверности различий (p) с использованием критерия Манна - Уитни для независимых групп и критерия Уилкоксона - для зависимых. Для этой цели применяли персональный компьютер с пакетом прикладных программ «Statistica 6.0» и Excel (Microsoft, 2003).

\section{Результаты}

Согласно современным представлениям о патофизиологии и патоморфологии течения травматической болезни, к первому периоду относится разгар системного воспалительного ответа [ Дерябин, 1983; Альфонсова и др., 2014]. Этот период характеризу- 
ется развитием полиорганной дисфункцией/недостаточностью. Длительность этого периода в среднем занимает 2-3 суток.

Затем отмечается развитие второго периода, который называется периодом относительной стабилизации жизненно важных функций.

Третий период травматической болезни начинается примерно после окончания 50 часов с момента получения травмы.

Конечный период травматической болезни - период реабилитации.

Одной из задач нашего исследования было уточнить периоды течения травматической болезни при огнестрельных и колото-резаных ранениях живота. Для достижения поставленной задачи бы проведен анализ течения послеоперационного периода 185 пострадавших, из них 89 (48,1 \%) и $96(51,9$ \%) с колото-резаными ранениями.

Как показывает оценка тяжести состояния по шкале ВПХ-СП. В результате оценки состояния тяжести раненых были получены следующие результаты: в группе с колото-резаными ранениями тяжесть состояния была оценена в $19 \pm 0,7$ баллов, в группе с огнестрельными ранениями - $23 \pm 0,7$ балла ( $<<0,05)$. Из представленных данных можно сделать заключение, что в группе с колото-резаными ранениями живота на момент поступления состояние было расценено как средняя степень тяжести, а при огнестрельных ранениях - как тяжелое.

Тяжесть состояния в обеих группах была обусловлена кровопотерей, травматическим шоком. Несмотря на тяжесть состояния, у всех раненых в момент поступления был диагностирован проникающий характер ранения, что явилось показанием для выполнения лапаротомии. Одновременно с выполнением оперативного вмешательства проводились противошоковые мероприятия. К моменту окончания операции тяжесть состояния раненых при колото-резаных ранениях составила $25 \pm 0,9$ балла, а в группе с огнестрельными ранениями - $27 \pm 0,8$ балла, т. е. группа пациентов с колото-резаными ранениями после выполнения операции из средней тяжести переходила в тяжелое состояние.

В группе с огнестрельными ранениями усугублялась тяжесть состояния, но при этом оно расценивалась как более тяжелое. По нашему мнению, это обусловлено реакцией на послеоперационную травму. При динамическом наблюдении за ранеными было установлено, что в первые 8-14 часов в группе раненых с колото-резаными ранениями живота была зарегистрирована положительная динамика, что проявилось снижением индекса ВПХ-СП с $25 \pm 0,9$ балла до $18 \pm 0,6$ балла (p < 0,05). Это может быть обусловлено эффективностью проводимых мероприятий в первый период травматической болезни. В то же время в группе раненых с огнестрельными ранениями живота, несмотря на проводимые мероприятия, существенной динамики в состоянии этих раненых отмечено не было. Это проявлялось в отсутствии динамики показателей индекса ВПХ-СП.

В дальнейшее время, в интервале 14-36 часов, существенной динамики в показателях индекса ВПХ-СП у раненых обеих групп зарегистрировано не было. Отмечены небольшие колебания этого показателя в пределах 1-4 баллов. В период с 36 до 48 часов у раненых обеих групп происходило резкое увеличение показателя индекса ВПХ-СП, который в группе с колото-резаными ранениями достиг $27 \pm 0,8$ балла, а в группе с огнестрельными ранениями - до $34 \pm 0,6$ баллов. Это может быть обусловлено активацией системного воспалительного ответа, который был более выражен в группе раненых с огнестрельными ранениями.

В дальнейшем были получены следующие результаты: на третьи-пятые сутки в группе раненых с колото-резаными ранениями живота отмечалось статистически достоверное снижение показателя индекса ВПХ-СП с $27 \pm 0,8$ до $19 \pm 0,4$ баллов (p < 0,05). Отсюда следует, что в данной группе происходило восстановление показателей гомеостаза, при этом общее состояние раненых можно было расценить уже не как тяжелое, а как средней степени тяжести. При этом в группе раненых с огнестрельными ранениями 
живота существенной динамики по исследуемой шкале получено не было. На шестые послеоперационные сутки в группе пациентов с колото-резаными ранениями существенной динамики по показателю индекса ВПХ-СП отмечено не было.

Полученные результаты соответствовали данным на третьи-пятые сутки. В то же время в группе пациентов с огнестрельными ранениями живота на данные сутки было зарегистрировано статистически достоверное уменьшение показателя индекса ВПХ-СП с $34 \pm 0,6$ до $25 \pm 0,4$ баллов $(\mathrm{p}<0,05)$.

На 7-9 послеоперационные сутки в обеих анализируемых группах было зарегистрировано дальнейшее статистически достоверное снижение индекса ВПХ-СП. Однако считаем нужным отметить, что в группе раненых с колото-резаными ранениями живота этот показатель снизился более значительно, по сравнению с данными, полученными в группе с огнестрельными ранениями живота.

Так, в группе с колото-резаными ранениями живота к девятым послеоперационным суткам этот показатель составил $8 \pm 0,8$ балла, а в группе с огнестрельными ранениями живота - только $25 \pm 0,7$ баллов $(\mathrm{p}<0,05)$. Полное восстановление индекса ВПХ-СП в группе пациентов с колото-резаными ранениями живота отмечено на 16 послеоперационные сутки, когда состояние раненых можно было расценить как удовлетворительное.

При этом в группе раненых с огнестрельными ранениями живота восстановление индекса ВПХ-СП происходило значительно позже - на 21 послеоперационные сутки, когда состояние раненых в данной группе было расценено как удовлетворительное. Ранения живота приводят к системной ишемии и реперфузии в тканях, это способствует выработке различных биологически-активных веществ, токсинов, фрагментов молекул белка. Выработка этих веществ приводит к развитию эндоксикоза.

Ранения живота, в силу своей тяжести, приводят к антигенной агрессии, которая является чрезмерной, переходящей в системную воспалительную реакцию. Одним из медиаторов эндотоксикоза является С-реактивный белок (СРБ). Данный белок синтезируется в печени в острую фазу воспаления. Как показывают наши исследования, уровень СРБ при огнестрельных ранениях живота во втором периоде травматической болезни зависел от фазы течения этого периода. Так, в фазу развертывания уровень СРБ составил $48,3 \pm 0,6$ мг/дл, а к завершению этого периода его уровень увеличивался до $73,2 \pm 0,5$ мг/дл.

Из полученных данных видно, что в первую фазу второго периода травматической болезни уровень СРБ возрастал более чем в семь раз, а во втором периоде - более чем в двенадцать раз. Помимо СРБ, при огнестрельных ранениях живота было отмечено статистически достоверное увеличение объема лейкоцитов в периферической крови, количество которых составило 13,4 $\pm 0,5 \times 109 / л$, и гипертермическая реакция до $38,6 \pm 0,70 \mathrm{C}$.

Необходимо отметить такой факт, что у раненых данной группы гипертермическая реакция не сопровождалась признаками присоединения инфекционного процесса. Такое течение было отмечено у 75 (84,2 \%) из 89 с ранениями в живот.

Кроме этого, во второй период течения травматической болезни у пациентов этой группы происходит дезинтеграция метаболических процессов организма, что проявляется в лактатном метаболическом ацидозе, который приводит к усилению повреждения клеточной мембраны и смерти клетки.

Все это приводит к кумуляции различных продуктов и развитию эндотоксикоза. Одним из показателей, который характеризует эндоксикоз, является показатель ПОЛ.

С этой целью нами было проведено исследование уровня малонового диальдегида, антиоксидантной активности и супероксиддисмутазы во второй период травматической болезни при различных ранениях живота, полученные результаты представлены в таблице. 
Уровень малонового диальдегида, антиоксидантной активности и супероксиддисмутазы при различных ранениях живота во второй период травматической болезни $(\mathrm{M} \pm \mathrm{m})$

Levels of malonic dialdehyde, antioxidant activity and superoxide dismutase in various abdominal injuries during the second period of traumatic disease $(\mathrm{M} \pm \mathrm{m})$

\begin{tabular}{|l|c|c|c|}
\hline \multirow{2}{*}{\multicolumn{1}{|c|}{ Показатели }} & \multicolumn{3}{|c|}{ Результаты в группах } \\
\cline { 2 - 4 } & $\begin{array}{c}\text { 3доровые } \\
(\mathrm{n}=25)\end{array}$ & $\begin{array}{c}\text { Огнестрельные ранения } \\
\text { живота (n = 89) }\end{array}$ & $\begin{array}{c}\text { Колото-резаные ранения } \\
\text { живота (n = 96) }\end{array}$ \\
\hline $\begin{array}{l}\text { Малоновый диальдегид } \\
\text { (нМоль/мл) }\end{array}$ & $3,6 \pm 0,7$ & $6,7 \pm 0,3^{*}$ & $4,3 \pm 0,6^{*}$ \\
\hline $\begin{array}{l}\text { Общая антиоксидантная } \\
\text { активность (\%) }\end{array}$ & $33,5 \pm 0,8$ & $16,4 \pm 0,4^{*}$ & $23,5 \pm 0,3^{*}$ \\
\hline $\begin{array}{l}\text { Супероксиддисмутаза } \\
\text { эритроцитов (Ед/г Нb) }\end{array}$ & $13585 \pm 0,4$ & $797,3 \pm 0,5^{*}$ & $995,7 \pm 0,4^{*}$ \\
\hline
\end{tabular}

Примечание: здесь и далее * - знак статистической достоверности $(\mathrm{p}<0,05)$, по сравнению с данными относительно здоровых людей.

Как видно из данных, представленных в таблице, у раненых в живот во второй период течения травматической болезни происходит статистически достоверное увеличение малонового диальдегида, который является продуктом распада арахидоновой и других полиненасыщенных жирных кислот. Этот процесс рассматривается как маркер оксидативного стресса и является показателем тяжелой степени эндогенной интоксикации. Кроме того, отмечается статистически достоверное уменьшение количества общей антиоксидантной активности, что свидетельствует об утрате защиты от действия свободных радикалов, что приводит к повреждению тканей, органов и развитию заболевания. О снижении защиты организма от повреждающего воздействия свободных радикалов, образующихся при усилении ПОЛ, свидетельствует и статистически достоверное уменьшение количества супероксиддисмутазы эритроцитов - металлофермента, который защищает клетки и является одним из основных антиоксидантов в организме человека. Изменения показателей ПОЛ, во второй период травматической болезни при огнестрельных ранениях в живот, характеризуют тяжелые состояния, которые проявляются эндогенной интоксикаций и приводят к развитию различных осложнений в ближайшем послеоперационном периоде. В результате проведенного анализа течения ближайшего послеоперационного периода, при огнестрельных абдоминальных ранениях было установлено, что полиорганная недостаточность в данные сроки была выявлена у 52 (58,4 \%) из 89 раненых, т. е. практически у половины из обследуемых. Это подтверждалось статистически достоверным увеличением содержания мочевины в сыворотке крови до $12,8 \pm 1,7$ мМоль/л $(\mathrm{p}<0,05)$ и креатинина сыворотки крови до $288 \pm 12$ мкМоль/л (р < 0,05).

Несколько другие результаты были получены в группе раненых с колото-резаными ранениями живота. Как и при огнестрельных ранениях живота, уровень СРБ зависел от фазы течения этого периода. Так, в фазу развертывания уровень СРБ в этой группе составил $12,1 \pm 0,4$ мг/дл, а к завершению этого периода его уровень увеличивался до 41,3 \pm 0,6 мг/дл. Из полученных данных видно, что в первую фазу второго периода травматической болезни уровень СРБ возрастал, однако это увеличение было менее выражено, чем при огнестрельных ранениях живота. При этом полученные результаты были статистически достоверными (p < 0,05). Помимо СРБ, при колото-резаных ранениях живота было отмечено статистически достоверное увеличение количества лейкоцитов в периферической крови - до 10,2 $\pm 0,5 \times 10^{9}$ /л, и гипертермическая реакция - до $37,8 \pm 0,4^{0} \mathrm{C}$. Как и в группе с огнестрельными ранениями живота, у этих обследуемых гипертермиче- 
ская реакция не сопровождалась признаками присоединения инфекционного процесса. Такое течение было отмечено у 56 (58,3\%) из 96 с ранениями в живот. Как и в группе с огнестрельными ранениями живота, в этой группе происходит дезинтеграция метаболических процессов организма. Вместе с тем необходимо отметить, что изменения этих показателей были менее выражены по сравнению с данными, полученными в группе с огнестрельными ранениями живота. Признаки полиорганной недостаточности у раненых этой группы были отмечены у 24 (25 \%) из 96 раненых. Развитие полиорганной недостаточности подтверждалось статистически достоверным увеличением содержания мочевины в сыворотке крови - до 9,6 \pm 1,7 мМоль/л $(\mathrm{p}<0,05)$, и креатинина сыворотки крови до $183 \pm 10$ мкМоль/л $(\mathrm{p}<0,05)$.

\section{Обсуждение}

Таким образом, проведенные исследования показывают, что травматическая болезнь при различных ранениях живота протекает по-разному и в различных временных рамках. Согласно современным представлениям о травматической болезни, первый период травматической болезни протекает в сроки примерно около 6 часов и характеризуется картиной травматического шока. Второй период развивается в сроки 12-48 часов и характеризуется развертыванием патологических механизмов полиорганной недостаточности [Назарова и др., 2018]. Выделяют неспецифические признаки травматической болезни, к которым относят повышение температуры, вялость, которые могут быть обусловлены нейроэндокринными механизмами [Смекалкина, 2010]. В результате проведенных исследований было установлено, что при колото-резаных ранениях живота травматическая болезнь протекает более легко и быстрее, чем при огнестрельных ранениях живота, это проявляется как клинически, так и лабораторными показателями. При этом, по нашим данным, развитие травматической болезни было зарегистрировано при изолированных повреждениях живота в случаях оценки состояния тяжести о шкале ВПХ-СП при колоторезаных ранениях в $19 \pm 0,7$ баллов, а при огнестрельных ранениях - в $23 \pm 0,7$ балла, что необходимо учитывать при ведении таких раненых. Всё это требует дальнейшего исследования.

\section{Вывод}

Развитие травматической болезни при различных абдоминальных ранениях происходит при изолированных повреждениях в случаях оценки состояния тяжести по шкале ВПХ-СП при колото-резаных ранениях в $19 \pm 0,7$ баллов, а при огнестрельных ранениях в $23 \pm 0,7$ балла. Травматическая болезнь протекает более тяжело при огнестрельных ранения живота. Так, у раненых в живот во второй период течения травматической болезни происходит статистически достоверное увеличение малонового диальдегида, который является продуктом распада арахидоновой и других полиненасыщенных жирных кислот. Эти процессы рассматриваются как маркер оксидативного стресса и являются показателем тяжелой степени эндогенной интоксикации. Кроме того, отмечается статистически достоверное уменьшение количества общей антиоксидантной активности, что свидетельствует об утрате защиты от действия свободных радикалов, что приводит к повреждению тканей, органов и развитию заболевания. О снижении защиты организма от повреждающего воздействия свободных радикалов, образующихся при усилении ПОЛ, свидетельствует и статистически достоверное уменьшение количества супероксиддисмутазы эритроцитов - металлофермента, который защищает клетки и является одним из основных антиоксидантов в организме человека. Изменения показателей ПОЛ во второй период травматической болезни при огнестрельных ранениях в живот характеризуют тяжелые состояния, которые проявляются эндогенной интоксикаций и приводят к развитию различных осложнений в ближайшем послеоперационном периоде. 
Несколько другие результаты были получены в группе раненых с колоторезаными ранениями живота. Как и при огнестрельных ранениях живота, уровень СРБ зависел от фазы течения этого периода. Так, в первую фазу второго периода травматической болезни уровень СРБ возрастал, однако это увеличение было менее выражено, чем при огнестрельных ранениях живота. Помимо СРБ, при колото-резаных ранениях живота было отмечено увеличение количества лейкоцитов в периферической крови и гипертермическая реакция. Как и в группе с огнестрельными ранениями живота, у этих обследуемых гипертермическая реакция не сопровождалась признаками присоединения инфекционного процесса. Как и в группе с огнестрельными ранениями живота, в этой группе происходит дезинтеграция метаболических процессов организма. Вместе с тем необходимо отметить, что изменения этих показателей были менее выражены по сравнению с данными, полученными в группе с огнестрельными ранениями живота.

\section{Список литературы}

1. Альфонсова Е.В., Забродина Л.А. 2014. Роль ацидоза в механизмах формирования полиорганной недостаточности. Ученые записки Забайкальского Государственного университета. Серия: Естественные науки; 54 (1): 82-88.

2. Гуманенко Е.К., Бояринцев В.В., Супрун Т.Ю., Ляшедько П.П. 1999. Объективная оценка тяжести травм. СПб: ВМедА. $110 \mathrm{c.}$

3. Дерябин И.И. Травматическая болезнь. 1983. Вестник хирургии им. И.И. Грекова; 131 (10): 75-79.

4. Масляков В.В., Костенко Е.В., Полковов С.В. 2014. Непосредственные результаты лечения закрытых травм печени, полученных вследствие дорожно-транспортных происшествий. Известия высших учебных заведений. Поволжский регион. Медицинские науки; 4: 54-62.

5. Назарова Е.О., Карпов С.М., Апагуни А.Э., Вышлова И.А. 2018. Современный взгляд на патогенетические механизмы травматической болезни при политравме. Вестник новых медицинских технологий. Электронное издание; 1. Публикация 7-1. URL: http://www.medtsu.tula.ru/VNMT/Bulletin/E2018-1/7-1.pdf (дата обращения: 12.01.2018). DOI: 10.24411/2075-4094-2018-15688.

6. Самохвалов И.М., Гаврилин С.В., Мешаков Д.П., Недомолкин С.В., Суворов В.В., Денисов А.В., Маркевич В.Ю., Супрун Т.Ю., Жирнова Н.А. 2018. Тяжелая сочетанная закрытая травма живота: особенности течения травматической болезни (сообщение первое). Вестник анестезиологии и реаниматологии; 15 (3): 34-40. DOI: 10.21292/2078-5658-2018-15-3-34-40.

7. Смекалкина Д.В. 2010. Современные аспекты травматической болезни у участников боевых действий. Хирургия. Журнал им. Н.И. Пирогова; 12: 89-93. $66-68$

8. Стальная И.Д., Гаришвили Т.Г. 1977 Современные методы в биохимии. - М.: Москва:

9. Стяжкина С.Н., Пелина Н.А., Саланкина А.Ю. 2018. Шок как осложнение травм при торакоабдоминальных травмах. Вопросы науки и образования; 1 (42): 6-12.

10. Тимербулатов Ш.В., Фаязов Р.Р., Смыр Р.А., Гатауллина Э.З., Шакиров Р.Ф., Идрисов Т.С. 2012 Определение объема и степени острой кровопотери. Журнал Медицинский вестник Башкортостана; 2: 69-72.

11. Штейнле А.В. 2010. От лигатурного лечения до реконструктивной ангиохирургии (к 250-летию сосудистого шва). Бюллетень сибирской медицины; 1 (9): 84-90. DOI: 10.20538/16820363-2010-1-84-90.

12. Эрметов А.Т., Исхаков Б.Р., Саидметов Ш.М., Исхаков Н.Б. 2017. Огнестрельные ранения живота с множественными повреждениями полых органов. Вестник экстренной медицины; 10: $68-61$.

\section{References}

1. Al'fonsova E.V., Zabrodina L.A. 2014. Rol' acidoza v mehanizmah formirovanija poliorgannoj nedostatochnosti [The role of acidosis in the mechanisms of formation of multi-organ insufficiency]. Scientists of notes of the Transbaikal State University. Series: Natural Sciences; 1 (54): 82-88. 
2. Gumanenko E.K., Bojarincev V.V., Suprun T.Ju., Ljashed'ko P.P. 1999. Obektivnaja ocenka tjazhesti travm [Objective assessment of the severity of injuries]. SPb.: WMedA: 110.

3. Derjabin I.I. 1983. Travmaticheskaja bolezn' [Traumatic illness]. I.I. Grekov Journal of Surgery; 10 (131): 75-79.

4. Masljakov V.V., Kostenko E.V., Polkovov S.V. 2014. Neposredstvennye rezul'taty lechenija zakrytyh travm pecheni, poluchennyh vsledstvie dorozhno-transportnyh proisshestvij [Immediate results of treatment of closed liver injuries resulting from traffic accidents]. News of higher education institutions. Volga region. Medical sciences; 4: 54-62.

5. Nazarova E.O., Karpov S.M., Apaguni A.Je., Vyshlova I.A. 2018. Sovremennyj vzgljad na patogeneticheskie mehanizmy travmaticheskoj bolezni pri politravme [Modern view of pathogenetic mechanisms of traumatic disease in polytraumas]. News of new medical technologies. Electronic edition; 1. Publication 7-1. URL: http://www.medtsu.tula.ru/VNMT/Bulletin/E2018-1/7-1.pdf (date of appeal: 12.01.2018). DOI: 10.24411/2075-4094-2018-15688.

6. Samohvalov I.M., Gavrilin S.V., Meshakov D.P., Nedomolkin S.V., Suvorov V.V., Denisov A.V., Markevich V.Ju., Suprun T.Ju., Zhirnova N.A. 2018. Tjazhelaja sochetannaja zakrytaja travma zhivota: osobennosti techenija travmaticheskoj bolezni (soobshhenie pervoe) [Severe combined closed abdominal trauma: peculiarities of the course of traumatic disease (message one)]. Journal of anesthesiology and resuscitation; 3 (15): 34-40. DOI: 10.21292/2078-5658-2018-15-3-34-40.

7. Smekalkina D.V. 2010. Sovremennye aspekty travmaticheskoj bolezni u uchastnikov boevyh dejstvij [Modern aspects of traumatic disease in participants of combat operations]. Surgery. Journal named after N.I. Pyrogov; 12: 89-93.

8. Stal'naja I.D., Garishvili T.G. 1977. Sovremennye metody v biohimii [Modern methods in biochemistry]. - Moscow: 66-68.

9. Stjazhkina S.N., Pelina N.A., Salankina A.Ju. 2018. Shok kak oslozhnenie travm pri torakoabdominal'nyh travmah [Shock as a complication of injuries in thoracoabdominal injuries]. Science and education issues; 1 (42): $6-12$.

10. Timerbulatov Sh.V., Fajazov R.R., Smyr R.A., Gataullina Je.Z., Shakirov R.F., Idrisov T.S. 2012. Opredelenie ob"ema i stepeni ostroj krovopoteri [Determination of the volume and extent of acute blood loss]. Journal Medical Journal of Bashkortostan; 2: 69-72.

11. Shtejnle A.V. 2010. Ot ligaturnogo lechenija do rekonstruktivnoj angiohirurgii (k 250-letiju sosudistogo shva) [From ligature treatment to reconstructive angiosurgery (to the 250th anniversary of vascular suture)]. Bulletin of Siberian Medicine; 9 (1): 84-90. DOI: 10.20538/1682-0363-2010-1-84-90.

12. Jermetov A.T., Ishakov B.R., Saidmetov Sh.M., Ishakov N.B. 2017. Ognestrel'nye ranenija zhivota s mnozhestvennymi povrezhdenijami polyh organov [Gunshot wounds to the abdomen with multiple hollow organ injuries]. The Journal of Emergency Medicine; 10: 68-61.

\section{ИНФОРМАЦИЯ ОБ АВТОРАХ}

Урядов Сергей Евгеньевич, доктор
медицинских наук, профессор кафедры
хирургических болезней Филиала частного
учреждения образовательной организации
высшего образования «Медицинский
университет «Реавиз», г. Саратов, Россия

Горбелик Виктор Ростиславович, кандидат медицинских наук, доцент кафедры хирургических болезней Филиала частного учреждения образовательной организации высшего образования «Медицинский университет «Реавиз», г. Саратов, Россия

\section{INFORMATION ABOUT THE AUTHORS}

Sergej E. Urjadov, Doctor of Medical Sciences, Associate Professor, Department of Surgical Diseases of a private institution educational organization of higher education «Medical University «Reaviz» in Saratov, Saratov, Russia

Viktor R. Gorbelik, candidate of medical sciences, associate professor, associate professor of the department of surgical diseases of a private institution educational organization of higher education «Medical University «Reaviz» in Saratov, Saratov, Russia 
Аллахяров Тенгис Чингизович, аспирант кафедры хирургических болезней Филиала частного учреждения образовательной организации высшего образования «Медицинский университет «Реавиз», г. Саратов, Россия

Шихмагомедов Мурат Альбертович, аспирант кафедры хирургических болезней Филиала частного учреждения образовательной организации высшего образования «Медицинский университет «Реавиз», г. Саратов, Россия

Куликов Сергей Александрович, аспирант кафедры хирургических болезней Филиала частного учреждения образовательной организации высшего образования «Медицинский университет «Реавиз», г. Саратов, Россия

Куликов Александр Витальевич, ассистент кафедры хирургических болезней Филиала частного учреждения образовательной организации высшего образования «Медицинский университет «Реавиз», г. Саратов, Россия
Tengis C. Allahjarov, assistant to the Department of Surgical Diseases of a private institution educational organization of higher education «Medical University «Reaviz» in Saratov, Saratov, Russia

Murat A. Shihmagomedov, graduate student of the Department of Surgical Diseases of a private institution educational organization of higher education «Medical University «Reaviz» in Saratov, Saratov, Russia

Sergej A. Kulikov, graduate student of the Department of Surgical Diseases of a private institution educational organization of higher education «Medical University «Reaviz» in Saratov, Saratov, Russia

Aleksandr V. Kulikov, assistant to the Department of Surgical Diseases of a private institution educational organization of higher education «Medical University «Reaviz» in Saratov, Saratov, Russia 